\title{
Short communication: Effect of on-farm feeding practices on rumen protected lysine products
}

\author{
P. Ji, ${ }^{*}$ H. A. Tucker, ${ }^{*}$ R. E. Clark, ${ }^{*}$ M. Miura, $†$ and C. S. Ballard ${ }^{*}$ \\ *William H. Miner Agricultural Research Institute, Chazy, NY 12921 \\ †Research Institute for Bioscience Products and Fine Chemicals, Ajinomoto Co. Inc., Kanagawa, Japan, 210-8681
}

\begin{abstract}
Two independent studies were conducted to determine whether mechanical mixing of total mixed ration (TMR) or TMR dry matter alters Lys release from 6 rumen-protected Lys (RPL) products $(\mathrm{A}, \mathrm{B}, \mathrm{C}, \mathrm{D}, \mathrm{E}$, and $\mathrm{F}$ ). In the first study, routine mixing procedures were simulated to determine if inclusion of RPL products in TMR altered in situ release of Lys. Following mixing, Dacron bags containing RPL products were ruminally incubated for $0,6,12$, or $24 \mathrm{~h}$ to determine Lys release. The second study occurred independently of the first, in which Lys release from RPL products was evaluated when incorporated into a TMR that differed in dry matter (DM) content. Bags containing TMR and RPL product mixture were stored at room temperature for $0,6,18$, and $24 \mathrm{~h}$ to simulate RPL product exposure to TMR when mixed and delivered once per day. Concentration of free Lys in both studies was determined using ultra-performance liquid chromatography. Following mechanical mixing, ruminal Lys release was significantly greater for $\mathrm{C}$ and tended to increase for $\mathrm{F}$. Mechanical mixing did not alter ruminal Lys release from other RPL products evaluated. Hours of ruminal incubation significantly altered Lys release for all products evaluated, and a significant interaction of mechanical mixing and hours of ruminal incubation was observed for A and C. Exposure to lower TMR DM (40.5 versus $51.8 \%$ ) significantly increased Lys release from B but did not alter Lys release from the other RPL products evaluated. Moreover, time of exposure to TMR significantly increased Lys release from all RPL products evaluated, and a significant interaction of TMR DM and time of exposure to TMR was observed for $\mathrm{B}$ and $\mathrm{E}$. These data suggest mechanical mixing and variation in TMR DM may compromise the rumen protection of RPL products; therefore, on-farm feeding practices may alter efficacy of RPL products in dairy rations.
\end{abstract}

Received December 5, 2014.

Accepted October 5, 2015.

${ }^{1}$ Corresponding author: ballard@whminer.com
Key words: rumen-protected lysine, total mixed ration dry matter, mechanical mixing

\section{Short Communication}

Lysine is recognized as one of the first-limiting AA for lactating dairy cows fed a typical corn-grain based diet in North America (NRC, 2001). Due to microbial utilization and limited Lys content of feed protein, successful Lys supplementation systems require efficient postruminal Lys release and effective protection from rumen degradation (Berthiaume et al., 2000). Commercially available rumen-protected Lys (RPL) products use encapsulation, matrix technology, or a combination of both to protect a Lys core from ruminal degradation, often involving a series of lipid- or fatty acid calcium salt-based rumen protection techniques (Ardaillon et al., 1989; Wu et al., 1989; Ardaillon and Franzoni, 1992; Cummings et al., 1993).

Protection technology and subsequent extent of protection from ruminal degradation varies between commercially available products (Rogers et al., 1987; Wu et al., 2012). In the rumen environment, coating protection efficiency is dependent on coat composition, smoothness of pellet surface, hardness of the inner core pellet, solubility of active ingredient, and pellet size (Wu and Papas, 1997). Differences in coating protection and its efficacy can affect resistance to surface damage and Lys release especially due to physical contact with TMR ingredients (Wu and Papas, 1997). Little research has focused on farm feeding practices and their potential to alter the efficacy of coating protection of commercially available RPL products. Therefore, the objectives of this study were to determine potential Lys release from RPL products induced by on-farm feeding conditions related to mixing of TMR and changes in TMR DM.

Six commercial RPL products (A: AjiPro-L, Ajinomoto Heartland Inc., Chicago, IL; B: AminoShure-L, Balchem Corporation, New Hampton, NY; C: LysiPEARL, Kemin Industries Inc., Des Moines, IA; D: Megamine-L, Church \& Dwight Co. Inc., Princeton, NJ; E: MetaboLys, H. J. Baker \& Bro. Inc., Westport, CT; F: USA Lysine, Land O'Lakes Inc., Arden Hills, MN) were 
used in 2 independent studies with completely randomized designs and split-plot arrangement of treatments to assess Lys release from each RPL product exposed to simulated on-farm feeding conditions. These studies were conducted at the William H. Miner Agricultural Research Institute (Chazy, NY), and the standard operating procedure for in situ digestion using cannulated cattle was approved by the William H. Miner Agricultural Research Institute Animal Care and Use Committee. Manufacturing companies were contacted before the start of both experiments and allowed to review and comment on the methodology. All products were sourced from the manufacturing company 1 mo before the start of the study, January 18, 2012. To characterize RPL products, free L-Lys was measured (UPLC System, Waters Corporation, Milford, MA), specific gravity was determined (AccuPyc 1330 Pycnometer, Micromeritics Instrument Corporation, Norcross, GA), particle size distribution was measured (Ro-Tap RX-29 sieve shaker; Laval Lab Inc., Laval, Quebec, Canada), and manufacturing details were summarized (Table 1).

To assess the effect of mechanical mixing of TMR on Lys release from RPL products, a Super Data Ranger (American Calan Inc., Northwood, NH) using paddle mixing was used to simulate the mechanical mixing force of a commercial farm TMR mixer. Each RPL product was weighed $(1.00 \pm 0.03 \mathrm{~g})$ and heat-sealed into Dacron bags $(5 \mathrm{~cm} \times 10 \mathrm{~cm}$, RPL product retention in bag, Table 1; Ankom Technology, Macedon,
NY) to allow for recovery of RPL product posttreatment. Triplicates of Dacron bags were prepared for each combination of RPL product, mixing treatment, load, and incubation time. Blanks, in triplicate, were also included at each combination of mixing treatment, load, and incubation time. Dacron bags were either placed in a Super Data Ranger (American Calan Inc.) containing $350 \mathrm{~kg}$ of TMR (Table 2) and mixed at full speed (6.5 rotations per minute) for $6 \mathrm{~min}$ (MIX) or placed into a barrel, gently incorporated with TMR, and allowed to sit for $6 \mathrm{~min}(\mathrm{CON})$. This procedure was repeated to allow for replicate loads $(\mathrm{n}=3)$. Dacron bags from both treatments were removed from the surrounding TMR and randomly allotted to ruminal incubation times $(0,6,12$, and $24 \mathrm{~h})$. Dacron bags were then placed in a weighted mesh bag, and submerged in the ventral ruminal sac of one of 3 multiparous rumen-cannulated Holstein cows (DIM $=202$ $\pm 8 \mathrm{~d} ; 34.5 \pm 0.9 \mathrm{~kg} / \mathrm{d}$ milk) housed in a free-stall pen and fed the same corn silage-based diet once daily at $0600 \mathrm{~h}$. Bags were incubated in reverse order (i.e., $24 \mathrm{~h}$ bags were inserted first) and removed simultaneously following incubation, gently washed in cold water by hand, and allowed to air-dry at room temperature $(>24 \mathrm{~h})$. Bags at $0 \mathrm{~h}$ were not placed in the rumen but were exposed to the same handling and washing procedures as those bags undergoing rumen incubation. Once dry, RPL residues including those from 0 -h bags were acid hydrolyzed (AOAC method 954.02; AOAC

Table 1. Characterization of rumen-protected Lys products

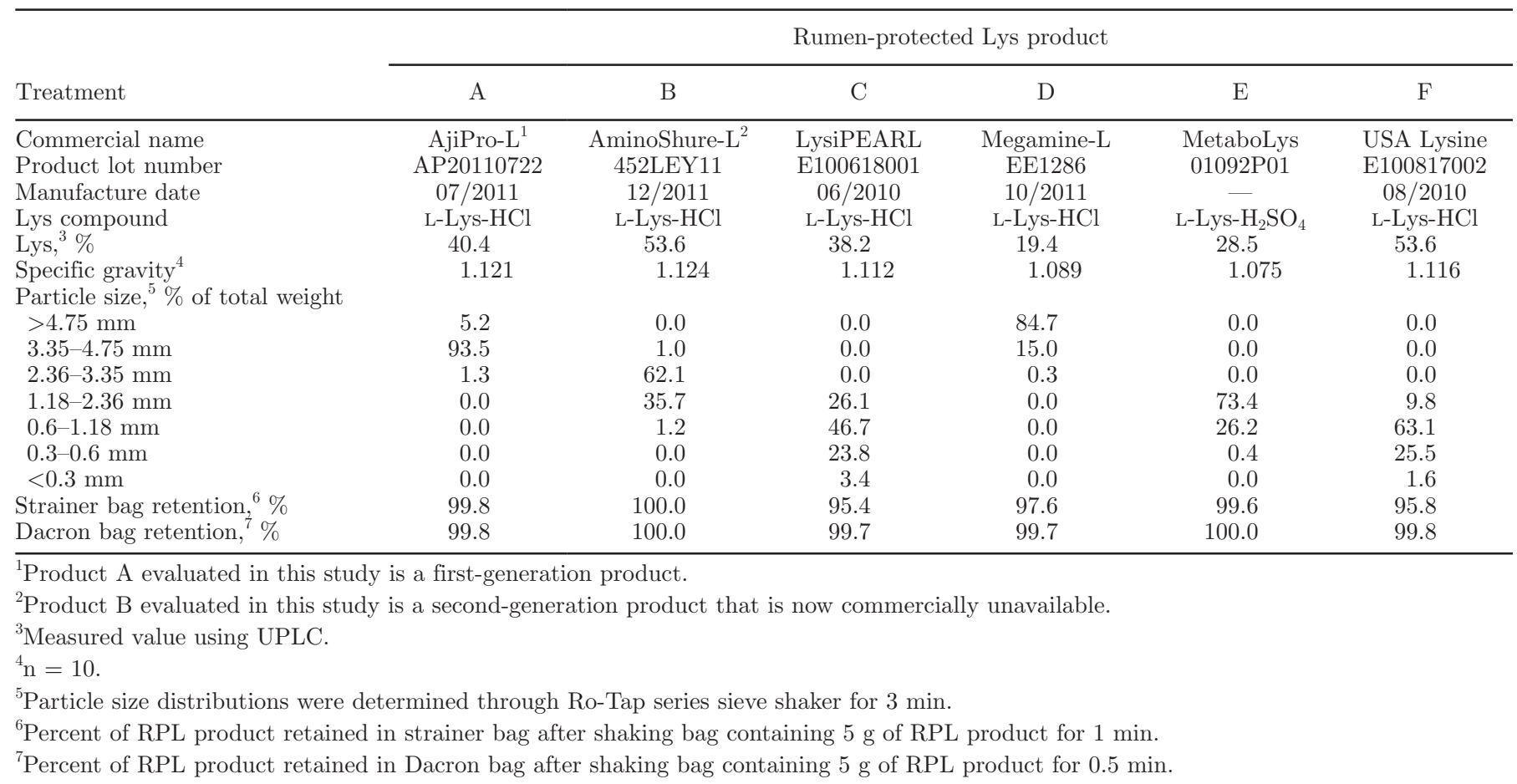


International, 2009), filtered $(0.45-\mu \mathrm{m}$ disc filter; GL Chromatodisc 25A polyolefin membrane, GL Science Inc., Tokyo, Japan), stored at $-20^{\circ} \mathrm{C}$ immediately, and within $1 \mathrm{~d}$ transferred to $-80^{\circ} \mathrm{C}$ until Lys content was quantified by UPLC. Lysine analysis was performed by Ajinomoto Co. Inc. with all RPL residues labeled so that the analyst was blind to treatment. For determination of free Lys, RPL residues were pre-diluted (20- or 40-fold) with Milli-Q water, derivatized using AccQ Tag Ultra reagent (Waters Corporation) then analyzed (Acquity UPLC System equipped with UV detector; Waters Corporation). Norvaline was used as an internal standard to adjust for dilution during derivatization. Lysine recoveries from acid hydrolysis were as follows: $\mathrm{F}(98.4 \pm 1.2 \%)$, B $(92.6 \pm 3.5 \%)$, E $(91.0 \pm 0.9 \%), \mathrm{A}(90.5 \pm 1.6 \%), \mathrm{C}(88.7 \pm 2.2 \%)$, and $\mathrm{D}(81.5 \pm 2.1 \%)$. Ruminal Lys release was determined by dividing Lys concentration of RPL products following ruminal incubation by the concentration of Lys in RPL products not exposed to the rumen environment.

To assess the effect of TMR DM on Lys release from the products, a TMR consisting of brown midrib corn silage and grass silage as the major forage sources was formulated for $52 \% \mathrm{DM}$ (Table 2; high). To reduce TMR DM, water was added to the high treatment to reduce DM content to $42 \%$ (low). Three loads (350 kg/ load) of each TMR type were prepared using a Super Data Ranger (American Calan Inc.) and sampled to analyze for DM, pH, and nutrient composition (Cumberland Valley Analytical Services Inc., Hagerstown, MD; Table 2). Aliquots $(2.00 \pm 0.05 \mathrm{~g})$ of each RPL product were weighed into sealable plastic bags (3.78 L) with duplicates for each combination of diet DM content, load, RPL product, and time point. Duplicate bags without RPL products were also used for each combination of diet DM content, load, and time point to serve as a control.

Samples of TMR $(200 \pm 1 \mathrm{~g})$ from each load of each treatment were transferred to plastic bags containing RPL products and shaken (30 s) to mix RPL products in TMR. After shaking, the bags were stored at room temperature $\left(21^{\circ} \mathrm{C}\right)$, unsealed, for $0,6,18$, and $24 \mathrm{~h}$. The same procedure was conducted for control samples (TMR only). At each time point, bag contents were transferred to a strainer bag $(15 \mathrm{~cm} \times 17 \mathrm{~cm} \times 25 \mathrm{~cm}$, RPL product retention in bag, Table 1; Hakugen, Tokyo, Japan) and submerged in $1 \mathrm{~L}$ of Arg solution (500 $\mathrm{mg} / \mathrm{L}$ ) for $1 \mathrm{~min}$. L-Arginine concentration was used as an internal standard to adjust for the potential dilution effect induced by additional water derived from TMR. A portion $(10 \mathrm{~mL})$ of the solution was filtered $(0.45$ $\mu \mathrm{m}$ disc filter; GL Chromatodisc 25A polyolefin membrane, GL Science Inc.), subsampled, stored at $-20^{\circ} \mathrm{C}$ immediately, and within $1 \mathrm{~d}$ transferred to $-80^{\circ} \mathrm{C}$ for
Table 2. Characterization of ration

\begin{tabular}{lc}
\hline Item & TMR \\
\hline Ingredient, \% on DM basis & \\
Brown midrib corn silage & 25.0 \\
Haylage & 25.0 \\
Corn meal & 10.0 \\
Concentrate mix & 40.0 \\
Composition ${ }^{1}$ & \\
DM, \% & $40.5 \pm 0.32$ \\
CP, $\%$ & $18.5 \pm 0.38$ \\
ADF, \% & $19.8 \pm 0.85$ \\
NDF, \% & $31.9 \pm 0.71$ \\
NFC, \% & $38.9 \pm 0.66$ \\
NE, Mcal/kg & $1.71 \pm 0.01$ \\
pH & $4.8 \pm 0.0$ \\
\hline
\end{tabular}

${ }^{1} \mathrm{n}=3$.

long-term storage. Lysine analysis was performed by Ajinomoto Co. Inc. with all samples labeled so that analyst was blind to treatment. Free Lys concentrations were determined as described previously, with the addition of Arg being used to normalize Lys dilution induced by sample soaking. Lysine release from RPL products at each time point was determined by dividing Lys concentration of samples containing RPL products (corrected for Lys release from TMR without RPL products) by the concentration of Lys in the RPL products.

Results from both studies were analyzed separately for each RPL product as a split-plot arrangement of treatments in a completely randomized design using the MIXED procedure of SAS (SAS 9.2 version, SAS Institute Inc., Cary, NC) with treatment (mixing or TMR DM) as the main plot and time (ruminal incubation or exposure to TMR) as subplots. The fixed effects in the model were treatment, time, and their interactions, whereas load within treatment was used as the error term. Least squares means were separated using Tukey's procedure when a significant $F$-test $(P<0.05)$ was detected. Significance was declared at $P \leq 0.05$ and tendency at $0.05<P \leq 0.10$.

Mechanical mixing of TMR significantly $(P<0.01)$ increased ruminal Lys release from C (75.2 vs. $68.4 \pm$ $0.7 \%$, average of 4 time points), whereas it tended ( $P=$ $0.08)$ to increase ruminal Lys release from F (75.9 vs. $72.6 \pm 1.0 \%$; Table 3). Initial and final Lys concentrations are outlined in Supplemental Table S1 (http:// dx.doi.org/10.3168/jds.2014-9197). The observed increases in ruminal Lys release due to mechanical mixing may be due to friability of the affected RPL products. Though friability of the products was not assessed, physical abrasion as a result of mechanical mixing may have damaged the coating on the RPL particles exposing the protected Lys core resulting in ruminal Lys release. As expected, in situ incubation 
Table 3. Effect of mixing on in situ Lys release (\%) of rumen-protected Lys (RPL) products following $0,6,12$, and $24 \mathrm{~h}$ of ruminal incubation

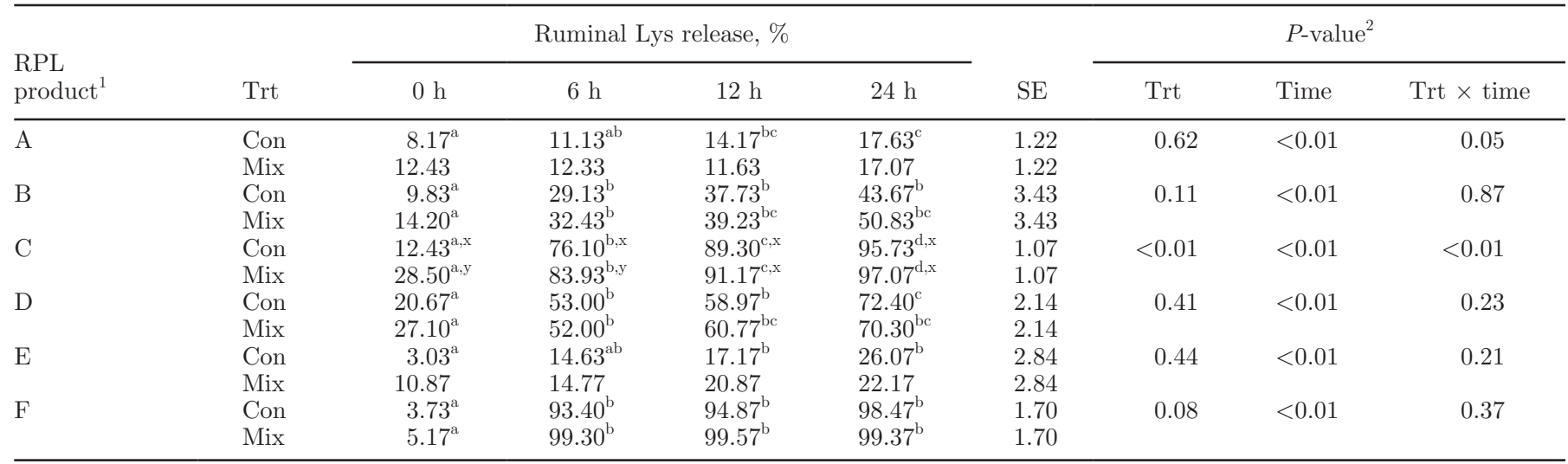

${ }^{\mathrm{a}-\mathrm{d}}$ Values in the same row with different superscripts are different $(P<0.05)$.

${ }^{\mathrm{x}, \mathrm{y}}$ Values in the same column of the same RPL product with different superscripts are different $(P<0.05)$.

${ }^{1} \mathrm{~A}=$ AjiPro-L, Ajinomoto Heartland Inc., Chicago, IL; B = AminoShure-L, Balchem Corporation, New Hampton, NY; C = LysiPEARL, Kemin Industries Inc., Des Moines, IA; D = Megamine-L, Church \& Dwight Co. Inc., Princeton, NJ; E = MetaboLys, H. J. Baker \& Bro. Inc., Westport, CT; F = USA Lysine, Land O'Lakes Inc., Arden Hills, MN.

${ }^{2}$ Trt $=$ main effect of treatment; Trt $\times$ time $=$ interaction of treatment by time

time significantly increased $(P<0.01)$ Lys release for all RPL products evaluated, being numerically greatest following $24 \mathrm{~h}$. Significant $(P \leq 0.05)$ treatment by time interactions were observed with $\mathrm{A}$ and $\mathrm{C}$. Ruminal Lys release was greatest for the 0 and $6 \mathrm{~h}$ time points with mixing; however, after 12 and $24 \mathrm{~h}$, ruminal Lys release was less with mixing for A. Lysine release was greater with mixing at all in situ time points for C.

When TMR DM content was altered, average DM of the low treatment was $40.5 \pm 0.3 \%$ and high averaged $51.8 \pm 0.4 \%$; in addition, $\mathrm{pH}$ averaged $4.8 \pm 0.0$ across all loads of all treatments at $0 \mathrm{~h}$ (Table 2). Decreasing
TMR DM significantly increased $(P<0.01)$ Lys release from B (3.16 vs. $6.62 \pm 0.37 \%$ ), but Lys release from other RPL products did not differ (Table 4). Time RPL products were exposed to TMR significantly increased $(P \leq 0.04)$ Lys release for all RPL products evaluated regardless of DM content, being numerically greatest at 24 h. Significant $(P \leq 0.02)$ treatment by time interactions were observed with $\mathrm{B}$ and E. Lysine release was greater in the low TMR at all time points except $0 \mathrm{~h}$ for B. Lysine release was greatest at 0 and $24 \mathrm{~h}$ in the high TMR for E, whereas it was greatest at 6 and $18 \mathrm{~h}$ in the low TMR.

Table 4. Lysine release (\%) of rumen-protected Lys (RPL) products at $0,6,18$, and $24 \mathrm{~h}$ after mixing with TMR varying in DM content

\begin{tabular}{|c|c|c|c|c|c|c|c|c|c|}
\hline \multirow{2}{*}{$\begin{array}{l}\text { RPL } \\
\text { product }^{1}\end{array}$} & \multirow{2}{*}{$\begin{array}{l}\text { DM } \\
\text { content }\end{array}$} & \multicolumn{4}{|c|}{ Lys release, \% } & \multirow[b]{2}{*}{$\mathrm{SE}$} & \multicolumn{3}{|c|}{$P$-value ${ }^{2}$} \\
\hline & & $0 \mathrm{~h}$ & $6 \mathrm{~h}$ & $18 \mathrm{~h}$ & $24 \mathrm{~h}$ & & Trt & Time & Trt $\times$ Time \\
\hline A & High & 0.77 & 0.83 & 1.28 & 1.02 & 0.33 & & & \\
\hline \multirow[t]{2}{*}{ B } & Low & $0.00^{\mathrm{a}, \mathrm{x}}$ & $1.60^{\mathrm{a}, \mathrm{x}}$ & $9.64^{\mathrm{b}, \mathrm{x}}$ & $15.33^{\mathrm{c}, \mathrm{x}}$ & 0.74 & $<0.01$ & $<0.01$ & $<0.01$ \\
\hline & High & $0.44^{\mathrm{a}, \mathrm{x}}$ & $1.27^{\mathrm{ab}, \mathrm{x}}$ & $4.49^{\mathrm{bc}, \mathrm{y}}$ & $6.43^{\mathrm{c}, \mathrm{y}}$ & 0.74 & & & \\
\hline $\mathrm{C}$ & Low & $7.96^{\mathrm{a}}$ & $43.38^{\mathrm{b}}$ & $50.34^{\mathrm{b}}$ & $51.75^{\mathrm{b}}$ & 2.29 & 0.87 & $<0.01$ & 0.67 \\
\hline $\mathrm{D}$ & High & $3.69^{\mathrm{a}}$ & $8.50^{\mathrm{a}}$ & $17.00^{\mathrm{b}}$ & $20.10^{\mathrm{b}}$ & 1.43 & & & \\
\hline \multirow[t]{2}{*}{$\mathrm{E}$} & Low & $0.19^{\mathrm{a}}$ & $1.34^{\mathrm{ab}}$ & $2.85^{\mathrm{bc}}$ & $3.61^{\mathrm{c}}$ & 0.39 & 0.96 & $<0.01$ & 0.02 \\
\hline & High & $1.42^{\mathrm{a}}$ & $0.37^{\mathrm{a}}$ & $1.91^{\mathrm{a}}$ & $4.22^{\mathrm{b}}$ & 0.39 & & & \\
\hline \multirow[t]{2}{*}{$\mathrm{F}$} & Low & $0.36^{\mathrm{a}}$ & $57.74^{\mathrm{b}}$ & $57.76^{\mathrm{b}}$ & $55.13^{\mathrm{b}}$ & 3.21 & 0.78 & $<0.01$ & 0.76 \\
\hline & High & $0.58^{\mathrm{a}}$ & $60.68^{\mathrm{b}}$ & $56.33^{\mathrm{b}}$ & $57.57^{\mathrm{b}}$ & 3.21 & & & \\
\hline
\end{tabular}

\footnotetext{
${ }^{\mathrm{a}-\mathrm{c}}$ Values in the same row with different superscripts are different $(P<0.05)$.

${ }^{\mathrm{x}, \mathrm{y}}$ Values in the same column of the same RPL product with different superscripts are different $(P<0.05)$.

${ }^{1} \mathrm{~A}=$ AjiPro-L, Ajinomoto Heartland Inc., Chicago, IL; B = AminoShure-L, Balchem Corporation, New Hampton, NY; C = LysiPEARL, Kemin Industries Inc., Des Moines, IA; D = Megamine-L, Church \& Dwight Co. Inc., Princeton, NJ; E = MetaboLys, H. J. Baker \& Bro. Inc., Westport, CT; F = USA Lysine, Land O’Lakes Inc., Arden Hills, MN.

${ }^{2}$ Trt $=$ main effect of treatment; Trt $\times$ time $=$ interaction of treatment by time.
} 
These data suggest that mechanical mixing and increasing the time RPL products are in contact with feed particles may compromise the efficacy of RPL products. Particle size (Table 1) and protective coating of RPL products may influence their vulnerability to mixing procedures and exposure to feed particles. Coating protection efficiency is highly dependent on several factors including coating composition, smoothness of pellet surface, and pellet size (Wu and Papas, 1997). Ruminal degradation of the lipid coating of the RPL products may account for some of the observed Lys loss as research assessing the efficacy of prilled fat to protect Lys from ruminal degradation observed a similar effect of time, with Lys recovery being reduced at $6 \mathrm{~h}$ and Lys recovery continuing to diminish through $24 \mathrm{~h}$ (Block and Jenkins, 1994). This suggests that increased retention time in the rumen leads to increased microbial degradation of the protective coating. Combined, these data clearly suggest mechanical mixing and variation in TMR DM may alter Lys release from some RPL products. These data also indicate that the amount of time RPL products are in contact with either ruminal fluid or TMR significantly reduces Lys content in products.

Despite differences in Lys release among RPL products, inferences regarding the effect of this study's treatments on bioavailability of the RPL products should not be made due to the limited scope of this study, as altered protection of Lys does not determine delivery of Lys to the blood of the cow (Block and Jenkins, 1994). For RPL products, retention time in the rumen is dependent on their particle size and specific gravity (Allen and Mertens, 1988) and particle size of RPL products varied greatly (Table 1). Undoubtedly, the treatments imposed in this study minimally challenged the RPL products when compared with commercial farm feeding practices. However, this study clearly suggests mechanical feed mixing and exposure to TMR over time may damage the protective coating and reduce efficacy of RPL products.

\section{ACKNOWLEDGMENTS}

The authors acknowledge Ajinomoto Heartland Inc. (Chicago, IL) for funding of these studies and Ajinomoto Heartland Inc. (Chicago, IL), Balchem Corporation (New Hampton, NY), Kemin Industries, Inc. (Des Moines, IA), Church \& Dwight Co. Inc. (Princeton, NJ), H. J. Baker \& Bro. Inc. (Westport, CT), and Land O'Lakes Inc. (Arden Hills, MN) for providing products for these studies.

\section{REFERENCES}

Allen, M. S., and D. R. Mertens. 1988. Evaluation of constraints on fiber digestion by rumen microbes. J. Nutr. 118:261-270.

AOAC International. 2009. Official Method, 954.02: Fat (crude) or ether extract in pet food. Official Methods of Analysis of AOAC International. Chapter 4, page 40. AOAC Int., Gaithersburg, MD.

Ardaillon, P., P. Antant, P. Bourrain, and A. Cartillier. 1989. Compositions for coating feedstuff additives thus coated. Rhone-Poulenc Sante, assignee. US Pat. No. 4877621.

Ardaillon, P., and C. Franzoni. 1992. Enzymatically degradable coating compositions for feed additives intended for ruminants. Foodsmith Corp., assignee. US Pat. No. 5098719.

Berthiaume, R., H. Lapierre, M. Stevenson, N. Cote, and B. W. McBride. 2000. Comparison of the in situ and in vivo intestinal disappearance of ruminally protected methionine. J. Dairy Sci. 83:2049-2056.

Block, S. M., and T. C. Jenkins. 1994. The use of prilled fat to coat and protect amino acids from ruminal degradation. J. Sci. Food Agric. 65:441-447.

Cummings, K. R., T. F. Sweeney, J. W. Dynes, and G. J. Gutowski. 1993. Production of dietary fatty acid salt compositions. Church and Dwight Co., assignee. US Pat. No. 5234701.

NRC. 2001. Nutrient Requirements of Dairy Cattle. 7th rev. ed. Natl. Acad. Sci., Washington, DC.

Rogers, J. A., U. Krishnamoorthy, and C. J. Sniffen. 1987. Plasma amino acids and milk protein production by cows fed rumen-protected methionine and lysine. J. Dairy Sci. 70:789-798.

Wu, S. H., and A. Papas. 1997. Rumen-stable delivery systems. Adv. Drug Deliv. Rev. 28:323-334.

Wu, S. H. W., S. K. Kirk, K. P. Perry, E. P. Smith, Y.-H. Chang, and W. L. Jenkins. 1989. Rumen-stable pellets. Rhone-Poulenc Nutrition Animale, assignee. US Pat. No. 4837004.

Wu, Z., J. K. Bernard, R. B. Eggleston, and T. C. Jenkins. 2012. Ruminal escape and intestinal digestibility of ruminally protected lysine supplements differing in oleic acid and lysine concentrations. J. Dairy Sci. 95:2680-2684. 